\title{
Le nouvel anti-christianisme. Entretiens avec Marc Leboucher
}

Paris, Desclée de Brouwer, 2005, 150 p.

Nicolas de Bremond d'Ars

\section{CpenEdition}

\section{Journals}

Édition électronique

URL : http://journals.openedition.org/assr/6962

DOI : $10.4000 /$ assr.6962

ISSN : $1777-5825$

Éditeur

Éditions de l'EHESS

Édition imprimée

Date de publication : 1 juin 2007

ISBN : 978-2-7132-2143-9

ISSN : 0335-5985

Référence électronique

Nicolas de Bremond d'Ars, "Le nouvel anti-christianisme. Entretiens avec Marc Leboucher », Archives de sciences sociales des religions [En ligne], 138 | avril - juin 2007, document 138-73, mis en ligne le 04 décembre 2013, consulté le 21 septembre 2020. URL : http://journals.openedition.org/assr/6962 ; DOI : https://doi.org/10.4000/assr.6962

Ce document a été généré automatiquement le 21 septembre 2020.

(c) Archives de sciences sociales des religions 


\title{
Le nouvel anti-christianisme. Entretiens avec Marc Leboucher
}

Paris, Desclée de Brouwer, 2005, 150 p.

\author{
Nicolas de Bremond d'Ars
}

1 Quelques années après Le christianisme en accusation (Desclée de Brouwer, 2000), René Rémond reprend la question controversée de l'anti-christianisme, dans des entretiens avec Marc Leboucher. Quatre débats structurent le regard porté par R. Rémond sur la société française contemporaine autour du christianisme.

2 Le premier se déroule à partir et autour de la charge virulente du philosophe Michel Onfray contre l'anthropologie chrétienne, et s'étend sur le problème de la régulation politique des mœurs. Le deuxième débat s'interroge sur l'irruption du communautarisme sur la scène publique comme possibilité socio-politique. Il permet de revisiter l'histoire conflictuelle de l'Église catholique dans la France républicaine. Tout naturellement, ces perspectives engagent un troisième débat sur la place des religions et du fait religieux dans la construction européenne, et passent en revue des controverses récentes (place de la Turquie, constitution européenne, affaire Buttiglione, etc.). L'ouvrage s'achève sur un éloge de la conscience, qui insiste notamment sur le discernement dons les sujets catholiques doivent faire preuve, tant à l'égard de la société politique qu'à l'égard des positions du Magistère romain.

3 La forme des entretiens choisie pour exposer les analyses et convictions de l'auteur ne convient que très modérément à la synthèse. La part la plus importante (quarantequatre pages) est consacrée à la discussion sur les positions polémiques de Michel Onfray. C'est la question européenne, pourtant moins développée, qui justifie le titre de l'ouvrage. R. Rémond montre que la dénonciation de Michel Onfray reprend deux arguments classiques contre le christianisme. D'une part, la morale «judéochrétienne " entraverait la liberté de mener sa vie à sa guise, en imposant une restriction de jouissance (une ascèse) et un frein aux désirs charnels. L'Église catholique confisquerait le bonheur humain. Cette position serait renforcée par une restriction politique : le christianisme engagerait les individus sur la voie d'une soumission aux pouvoirs établis. Le monothéisme s'apparenterait par là à un totalitarisme. La société 
païenne antique, polythéiste, favoriserait au contraire la liberté et la tolérance. M. Onfray dénonce en particulier l'obscurantisme de l'Église catholique, qui serait hostile à la science et au progrès scientifique.

4 Tout en récusant une certaine étroitesse de pensée de M. Onfray, R. Rémond rend justice à l'argumentaire contre le moralisme de l'Église. Il reconnaît que celle-ci donne prise, y compris du côté des fidèles catholiques, à une telle critique: «l'Église paie probablement le prix d'un discours déséquilibré, car dans sa longue histoire, elle a passé peut-être plus de temps à définir les normes de conduite qu'à transmettre le message d'amour de l'Évangile» (p. 35). La période contemporaine, affirme-t-il, a du mal à recevoir et tolérer une forme de discours qui renvoie à une volonté de régulation autoritaire des consciences. Cela dispense-t-il les penseurs antichrétiens de faire preuve de rigueur scientifique, et d'une prudence sur les conséquences sociales de leur position? Certainement pas, déclare-t-il, et l'Église catholique remplit à juste titre son rôle d'interpellation des consciences.

De ce point de vue, le débat sur le communautarisme devrait rassurer les tenants de la laïcité républicaine à la française : "Si la question est: les catholiques ont-ils à se comporter comme une communauté au sein de la communauté française? Ma réponse est négative » (p. 74). Le catholicisme demeurant la religion partagée par le plus grand nombre de Français, il est logique, selon R. Rémond, qu'il ne cherche ni le repli identitaire - certes légitimable par un passé de discrimination, rappelle-t-il -, ni l'ingérence dans les choix proprement politiques. Il est en revanche logique que l'Église catholique en France insiste sur la responsabilité des citoyens dans l'éducation à la conscience morale, et au respect de la liberté religieuse.

La construction européenne a-t-elle étendu le terrain d'affrontement séculaire? On serait tenté de le penser, avec les controverses passionnées autour des racines «religieuses» ou "spirituelles» de l'Europe. L'auteur souligne les deux temps de l'affaire. D'abord la mention du rôle historique des religions quant à la constitution de l'espace culturel européen. Au titre de l'Histoire, R. Rémond admet la légitimité de l'inscription. Puis, entrant en collision avec cette dimension, une revendication posée par certains pays d'inscrire la référence à Dieu dans les fondements constitutionnels, il affirme alors son opposition résolue.

7 En refermant ces pages, on éprouve une certaine perplexité. Si on admire la finesse et la pertinence des analyses de R. Rémond, si on salue son engagement chrétien mesuré et responsable, on s'interroge malgré tout sur l'objet de l'ouvrage. S'agit-il de dénoncer le sort fait aux catholiques en France, ou bien d'une volonté de dépasser le vieux débat anticlérical - qui se reporterait sur une dimension antireligieuse? En ce cas, les arguments qui ouvriraient sur les nouveaux défis posés par la modernité européenne, les transformations sociales, économiques et culturelles (pluralisme religieux, etc.), ne sont pas spécialement apparents. Les mises au point historiques et politiques contribueront sans nul doute à étayer les débats passionnels autour des faits religieux. Celui qui est intéressé par une prospective et un dépassement des problématiques antagonistes restera un peu sur sa faim. 